\title{
NILAI-NILAI PENDIDIKAN AKHLAK WANITA DARI PARA ISTRI NABI \\ (Analisis Surat Al-Ahzab Ayat 28-35 dalam Kitab Tafsir Al- Azhar Karya Buya Hamka)
}

\author{
Widiani Hidayati \\ Universitas Islam Indonesia, Yogyakarta, Indonesia \\ 20913048@students.uii.ac.id
}

\section{Faisal Saleh}

Universitas Islam Indonesia, Yogyakarta, Indonesia 20913041@students.uii.ac.id

DOI: 10.20885/tarbawi.vol12.iss2.art4

\begin{abstract}
This paper intends to discuss how the morals of the Prophet's wives, which are summarized in Surah Al-Ahzab verses 28-35, used as directions, references, and instructions for women. The wives of the Prophet are the mothers of religious people so that it should be used as an example by Muslims, especially for women. In analyzing Surat Al-Ahzab verses 28-35, the writer uses the library research approach, with the primary data source is Buya Hamka's book of Tafsir Al-Azhar. and for the secondary data, the writer uses various books and journals that are relevant with the topic. This paper concluded that according to Buya Hamka interpretation, the morals ordered by Allah SWT to women in Surat Al-Ahzab verses 28-35, is to choose the afterlife over the temporary world or implementing simple life, not to commit heinous acts towards others, such as condemning, cursing at people, stealing, slandering, because it can drop a woman's honor, speaking well, politely, firmly, not weak and flirtatious, staying at home, not overly made up and dressed up, worshiping (reading the Koran, giving charity, Fasting, Dhikr) with khusyu, and clear from all the qualities that defile the heart (envy, arrogance, envy, and greed)
\end{abstract}

Keyword: Morality, Tafsir, Character Education, Buya Hamka 


\section{$e^{\text {I-Tarbawj Widiani Hidayati \& Faisal Saleh }}$}

\section{Abstrak}

Tulisan ini hendak membahas bagaimana Akhlak Para Istri Rasulullah yang terangkum dalam Surat Al-Ahzab ayat 28-35, agar bisa dijadikan arahan, acuan dan petunjuk untuk wanita-wanita di zaman sekarang. Istri Nabi merupakan Ibunda bagi orang-orang beiman sehingga patut dijadikan teladan oleh umat islam terutama bagi kaum hawa. Dalam menganalisis Surat Al-Ahzab ayat 28-35 ini penulis menggunakan pendekatan Library Research, dengan sumber data primer Kitab Tafsir Al-Azhar karya Buya Hamka. dan Data Sekundernya penulis menggunakan berbagai buku dan jurnal yang relavan dengan judul tulisan. Kesimpulan dari tulisan ini adalah Akhlak yang diperintahkan oleh Allah SWT kepada para wanita dalam Surat Al-Ahzab ayat 28-35 menurut Buya Hamka dalam Kitab Al-Azhar yaitu Memilih kehidupan Akhirat daripada dunia atau menerapkan kehidupan yang sederhana, tidak melakukan perbuatan keji (mempergunjingkan orang lain, mencela, memaki orang, mencuri, memfitnah) karena dapat menjatuhkan kehormatan wanita, berbicara dengan baik, sopan, tegas tidak lemah gemulai, dan genit, berdiam di rumah, tidak berhias/berdandan berlebihan, beribadah (Membaca Al-Quran, Bersedekah, Berpuasa, Berdzikir) dengan khusyu, dan bersih dari segala sifat yang mengkotori hati (dengki, sombong, iri, dan tamak)

Kata kunci: Moralitas, Tafsir, Pendidikan Karakter, Buya Hamka

\section{PENDAHULUAN}

Peran wanita sangat penting bagi generasi bangsa. Ia akan melahirkan generasi-generasi berikutnya untuk menjadi penerus yang bermartabat. Dulu wanita sangat direndahkan, bahkan sampai dianggap aib oleh masyarakat. Pada masa arab jahiliyah wanita dieksekusi dan dikuburkan hidup-hidup, baik dikuburkan ketika lahir ataupun pada masa kanak-kanak 
(AlTaliyadi 2008 19). Pada Masa Yahudi kuno bahkan wanita dianggap sebagai najis, mereka dipenjara dalam rumah dan setiap benda yang mereka sentuh, baik makanan, pakaian, bejana atau binatang akan dianggap najis pula, setiap perbuatan amoral yang dilakukan lelaki, maka dosanya akan dibebankan kepada wanita, karena mereka menganggap wanita sebagai budak yang dikuasai.( Al-Taliyadi 2008, 17)

Islam datang menjadi penerang dalam permasalahan ini, Dalam Islam wanita memiliki keistimewaan dan kemuliaan. Islam merupakan agama yang sangat menghormati dan menghargai wanita dan menghapus tradisi Jahiliyah yang begitu melemahkan posisi perempuan. Dalam Islam, laki-laki dan perempuan dianggap sebagai hamba Allah SWT yang setara, bahkan wanita dan laki-laki saling melengkapi dan membutuhkan. Islam memperluas ruang peran dan memenuhi hal-hak perempuan secara sempurna, menghargai kemuliaan, dan derajatnya.(Al-Taliyadi 2008, 20)

Sebagai umat islam kita telah diberikan petunjuk untuk menjalani kehidupan di Dunia agar selamat di Dunia dan Akhirat. Petunjuk kita adalah Al-Qur'an. di dalamnya terdapat arahan-arahan bagaimana setiap muslim harus bersikap. arahan serta petunjuk tersebut juga dikuatkan oleh hadisthadist nabi. Nabi Muhammad SAW sebagai suri tauladan yang patut diikuti, karena Nabi Muhammad diutus oleh Allah SWT untuk menyempurnakan akhlak umat muslim. tentunya akhlak istri-istri nabi juga menjadi suri tauladan untuk para muslimah. Akhlak istri nabi sangat baik karena mendapatkan bimbingan langsung dari Rasulullah SAW dan dari Allah SAW melalui ayat-ayat Al-Qur'an. seharusnya wanita muslimah 


\section{$e^{\text {I-Tarbawj Widiani Hidayati \& Faisal Saleh }}$}

mengidolakan dan meneladani akhlak istri-istri Nabi, bukan meneladani orang-orang Barat seperti apa yang telah terjadi saat ini.

Akhlak wanita masa kini mengalami kemerosotan. banyak wanita yang saat ini keluar dari fitrahnya, tidak mengetahui jati dirinya, dan jauh dari akhlak yang telah dicontohkan oleh ibunda orang-orang beriman, yaitu istri-istri Nabi. Kini banyak wanita yang menyukai dan mengikuti gaya barat. padahal gaya barat sangat bertolak belakang dengan apa yang diajarkan oleh Islam. Kemerosotan Akhlak wanita Indonesia bisa dilihat dari berbagai masalah yang terjadi. salah satu faktanya adalah angka aborsi ilegal di Indonesia masih sangat tinggi, menurut data Komisi Perlindungan Anak Indonesia ( $\underline{\text { KPAI }}$ ) tahun 2020, ada 2 juta kasus setiap tahunnya dan 30\% dilakukan oleh kalangan remaja (Rochimawati dan Sumiyat, 2020). kita juga bisa melihat bagaimana banyak wanita menggunakan pakaian yang sepatutnya tidak digunakan keluar rumah, dan adat sopan santun yang semakin lama semakin memudar. Oleh karena itu penting bagi wanita untuk belajar kembali dan menata akhlaknya.

Allah SWT telah memberikan petunjuk kepada para wanita bagaimana caranya berakhlak. hal ini disampaikannya dalam Surat Al-Ahzab ayat 28-35. Ayat ini bukan hanya ditujukan untuk istri para Nabi, namun untuk kaum muslim terutama kaum wanita. Dalam artikel ini penulis akan membahas bagaimana akhlak wanita yang dianjurkan oleh Allah SWT kepada istri-istri Nabi yang patut diteladani oleh seluruh wanita muslimah.Penulis manganalisis Surat Al-Ahzab ayat 28-35 yang mengandung perintah-perintah Allah SWT 
kepada Istri Nabi dalam Kitab tafsir Al-Azhar karya Buya Hamka.

\section{METODE PENELITIAN}

Penelitian ini menggunakan pendekatan telaah perpustakaan (Library research). penelitian ini dilakukan untuk memperoleh informasi tentang akhlak wanita dalam surat AlAhzab ayat 28-35 yang bersumber dari bahan kepustakaan yang relevan. Sumber data dalam penelitian ini adalah AlQur'an dan Tafsir Al-Azhar karya Buya Hamka, sedangkan Data sekundernya adalah buku-buku serta jurnal-jurnal ilmiah yang relavan analisi data yang dilakukan yaitu dengan metode analisis Deduktif yaitu mengambil suatu kesimpulan dari situasi pengertian yang sifatnya umum menuju pengertian yang sifatnya khusus.

\section{HASIL DAN PEMBAHASAN}

\section{Biografi Buya Hamka}

Haji Abdul Malik Karim Amrullah yang lebih dikenal sebagai Buya Hamka, dilahirkan di kampung Molek, Desa Tanah Sirah, di tepi Danan Maninjau, Tanjung Raya, Sumatera Barat pada tangal 16 Februari 1908 M atau 13 Muharram 1362 H. Orangtuanya bernama Sheikh Abdul Karim Amrullah dan Siti Shafiyah Tanjung binti Haji Zakaria (Hidayat 2020,51). Ayahnya dikenal sebagai Haji Rasul bin Syekh Muhammad Amarullah bin Tuanku Abdullah Saleh. beliau merupakan 


\section{$e^{I-T a r b a w j ~ W i d i a n i ~ H i d a y a t i ~ \& ~ F a i s a l ~ S a l e h ~}$}

salah satu pelopor kebangkitan tokoh dan kaum muda Muhammadiyah di Minangkabau. Buya Hamka memiliki hubungan dengan generasi pembaharu Islam di Minangkabau pada akhir abad 18 dan awal abad 19, dia berasal dari keturunan yang taat beragama (Nizar 2008,18)

Sejak kecil, Hamka belajar membaca Al-quran dan dasardasar Agama langsung dari ayahnya.(Fitri 2020, 46). Ketika tahun 1914 tepat pada usianya 6 Tahun, Hamka dibawa oleh ayahnya ke Padang panjang. Pada tahun 1916 salah satu murid Haji Rasul yang bernama Zainuddin Labay membuka sekolah Diniyyah Modern di Padang Panjang, jadilah Hamka sebagai salah satu murid di sana. Pada usia 8-15 tahun, ia mulai belajar agama di sekolah Diniyyah School dan Sumatera Thawalib di Padang Panjang dan Parabek. Sumatera Thawalib adalah sebuah sekolah dan perguruan tinggi yang mengusahakan dan memajukan bermacam pengetahuan tentang Islam yang membawa kebaikan dan kemajuan di dunia dan akhirat (Roziqin 2009,53) Diantara gurunya adalah Syekh Ibrahim Musa Parabek, Engku Mudo Abdul Hamid, Sutan Marajo dan Zainuddin Labay el-Yunusy. Keadaan Padang Panjang pada saat itu ramai dengan penuntut ilmu agama Islam, di bawah pimpinan ayahnya sendiri. Pelaksanaan pendidikan waktu itu masih bersifat tradisional dengan menggunakan sistem halaqah (Nizar 2008, 20). Ditempat itulah Hamka mempelajari ilmu agama dan mendalami ilmu bahasa arab. Materi pendidikan masih berorientasi pada pengajian kitab-kitab klasik, seperti fiqh, nahwu, sharaf, bayan, manthiq, dan sebagainya

Ketika bersekolah di Sumatera Thawalib dan Parabek, Hamka sangat tertarik pada sejarah dan syair arab. Kehadiran 
Balai Pustaka dan Pustaka Zainaro di Minangkabau sangat membantunya untuk memenuhi keinginannya dalam membaca buku-buku sejarah berbahasa Melayu. Buya Hamka banyak belajar Pengetahuan agama secara otodidak (belajar sendiri), selain belajar ilmu agama, Hamka juga belajar otodidak dalam berbagai bidang ilmu pengetahuan seperti Sejarah, filsafat, sastra, politik, dan sosiologi baik Islam maupun Barat (Hamka 1974,46)

Hamka kemudian pergi ke Mekkah, Hamka pulang dari Mekkah pada tahun 1928 M. kepulangannya menjadikan ia lebih memahami bahasa Arab daripada sebelumnya, sehingga ia mampu membaca sejarah Islam tidak hanya dari kitab bahasa melayu saja. namun dia mengeksplor kitab-kitab berbahasa arab. Pada usianya 29 tahun, Hamka menjadi seorang guru agama di perkebunan Tebing Tinggi. Pada Tahun 1957-1958 beliau mengajar di Universitas Muhammadiyah Padang Panjang dan Universitas Islam Jakarta, Setelah itu dia menjabat sebagai guru besar di Universitas Mustopo Jakarta. dan dilantik menjadi Rektor Perguruan Tinggi Islam Jakarta (Raziqin 2009, 191). Selain itu pada tahun 1951-1960 Hamka menjabat sebagai seorang pegawai tinggi agama.

Hamka menerima beberapa anugerah tingkat nasional dan internasional seperti pada tahun 1958, beliau mendapatkan anugerah kehormatan Ustâdziyyah Fakhriyyah (Doctor Honoris Causa) dari Universitas Al-Azhar dalam rangka penghormatan untuk perjuangannya terhadap syi'ar Islam. Pada tahun 1974, beliau mendapat penghargaan atas pengabdiannya dalam mengembangkan kesastraan dari Universitas Kebangsaan Malaysia. selain itu beliau mendapatkan gelar Datuk Indono 


\section{$e^{\text {I-Tarbawj Widiani Hidayati \& Faisal Saleh }}$}

dan Pangeran Wiroguno (James R 2017, 243). Hamka memiliki Rasa keingintahuan yang besar, beliau dikenal sebagai ulama yang memiliki banyak pendengar. Karena beliau pandai dalam membawakan kajian keislaman dan mampu mencairkan suasana dengan bahasa-bahasanya yang memikat

Hamka tertarik dengan hampir semua ilmu keislaman, namun sejarah adalah yang paling dia senangi, Dalam tulisantulisan sejarahnya beliau memasukkan nilai-nilai filsafat (Jambak dan Fadhly 2018, 7)._selain itu dalam karya sejarahnya cenderung melakukan kategorisasi berdasarkan waktu. Hamka menutup mata untuk selamanya di Jakarta pada hari Jumat tanggal 24 Juli 1981 dikarenakan sakit diabetes.

\section{Kitab Tafsir Al-Azhar}

Tafsir al-Azhar adalah kitab tafsir karya Buya Hamka, Hamka menamianya Al-Azhar sesuai dengan nama masjid yang didirikan di Kebayoran Baru yang merupakan tanah halamannya.Penafsiran Hamka dimulai dari Juz 15 yaitu Surat Al-Kahf. Pada Senin, 27 Januari 1964 atau 12 Rabi'ul Awal 1383 Hamka ditangkap penguasa Orde Lama dengan tuduhan berkhianat terhadap tanah air dan dipenjara selama 2 tahun 7 bulan (Razikin 2009, 191). Hamka memanfaatkan waktunya di penjara untuk menulis dan menyempurnakan tafsir 30 juznya. Para ulama-pun banyak yang mendukungnya, seperti para utusan dari Aceh, Palembang, Sumatera Timur ulama, Mesir, Makassar, Banjarmasin, Jawa Timur, Nusa Tenggara Barat, Banjarmasin, dan lain-lain. Hamka menulis tafsirnya pada siang hari, dan malam harinya digunakan untuk bermunajat dan 
shalat tahajud. Pada tahun 1967 akhirnya Tafsir al-Azhar pertama kali diterbitkan.(Islah. Gusmian 2003, 60)

Tafsir ini menjelaskan latar belakang Buya hamka, dalam bukunya beliau menjelaskan watak masyarakat dan sosiobudaya yang terjadi saat itu. Tulisannya merekam kehidupan dan sejarah sosio-politik umat yang getir dan hamka menampakkan cita-citanya untuk mengangkat pentingnya dakwah di Nusantara. Karena ditahan di penjara ia memperkuat tekad perjuangannya, kekuatan dan semangat baru terhadap pola pikir dan pandangan hidupnya. Tafsir $\mathrm{Al}-$ Azhar ditulis berdasarkan pandangan dan kerangka manhaj yang jelas dengan merujuk pada kaidah Bahasa Arab, tafsiran salaf, asbâb al-nuzûl, nâsikh-mansûkh, Ilmu Hadis, Ilmu Fiqih dan sebagainya. Ia turut men-zahirkan kekuatan dan ijtihad dalam membandingkan dan menganalisis pemikiran madzhab (Hamka 2004, 3)

Tafsir ini merupakan pencapaian dan sumbangan terbesarnya dalam membangun pemikiran dan mengangkat tradisi ilmu yang melahirkan sejarah penting dalam penulisan tafsir di Nusantara. Adapun tujuan terpenting dalam penulisan Tafsir al-Azhar adalah untuk memperkuat dan memperkukuh hujjah para muballigh dan mendukung gerakan dakwah (Hamka 2004, 58) 


\section{$e^{\text {I-Tarbawj Widiani Hidayati \& Faisal Saleh }}$}

\section{Tafsir Buya Hamka Surat Al-Ahzab Ayat 28-35}

a. Surat al-Ahzab ayat 28-29

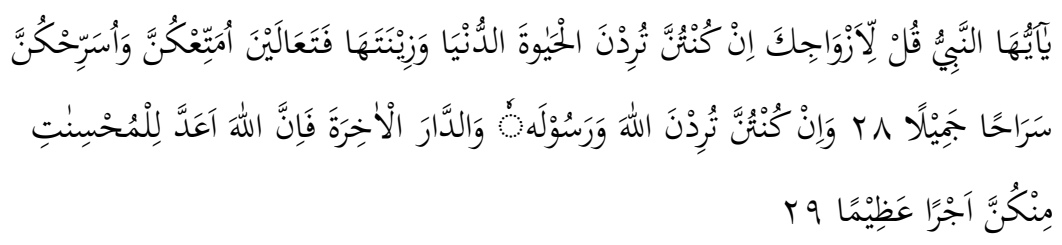

Artinya : Wahai Nabi Katakanlah kepada istri-istrimu, "Jika kamu menginginkan kehidupan di dunia dan perhiasannya, maka kemarilah agar kuberikan kepadamu mut'ah dan aku ceraikan kamu dengan cara yang baik." "Dan jika kamu menginginkan Allah dan Rasul-Nya dan negeri akhirat, maka sesungguhnya Allah menyediakan pahala yang besar bagi siapa yang berbuat baik diantara kamu."(QS Al-Ahzab :28-29)

Menurut Hamka dalam tafsir Al-Azhar menjelaskan, bahwa kedua ayat ini adalah ayat takhyiir, artinya disuruh untuk memilih. Dalam ayat ini istri-istri Rasulullah disuruh memilih antara memilih Allah SWT dan Rasul atau memilih kehidupan dunia dan perhiasannya. Jika mereka memilih bersama Rasulullah SAW dengan tujuan ingin dunia, keinginannya tidak akan tercapai, karena Rasulullah berjuang untuk berdakwah bukan untuk mengejar dunia, Kalau dunia yang mereka cari, maka bercerai secara baik sebagai obat hati. Tetapi jika istri-istri Nabi tersebut mau besama, membela Nabi dalam dakwah dan mencukupkan dunia apa adanya, maka hidup berumah tangga dengan selamat sampai dipisahkan oleh liang lahat. 
Asbabun nuzul dari ayat ini diantaranya adalah hadits yang diriwayatkan Bukhari dan Muslim. Menurut suatu riwayat, sebagaimana yang disalinkan oleh al-Qurthubi dalam tafsirnya, Rasulullah SAW disuruh untuk memilih, manakah yang lebih beliau sukai, apakah menjadi Nabi seperti Nabi sulaiman AS yang kaya raya atau memilih hidup miskin. Nabi Muhammad SAW memilih hidup diantara keduanya, yaitu makan sehari dan lapar sehari. hal ini dilakukan agar di waktu kenyang beliau bersyukur kepada Allah SWT, dan di waktu lapar atau berkekurangan beliau bersabar. Beliau hendak menunjukkan contoh tentang hidup yang sederhana, bersahaja, dan penuh dengan rasa syukur ('Hamka 2015, 194-197)

Selain itu ada juga hadist lain, yaitu Dari Aisyah ra mengatakan: "Rasulullah SAW bertanya kepadaku 'Wahai Aisyah, apakah engkau memiliki sesuatu untuk dimakan ?'Aku menjawab 'Wahai Rasulullah kita tidak memiliki apapun untuk dimakan pagi ini' kemudian Rasulullah SAW berkata 'kalau begitu aku akan berpuasa" (HR Muslim no. 1154).

Kita dapat menyimpulkan bahwa pendidikan akhlak dari para istri Nabi saw. menurut Hamka adalah, bahwa mereka lebih memilih Allah dan Rasul-Nya dan kehidupan akherat daripada dunia dan pehiasannya.

b. Surat al-Ahzab ayat 30-31

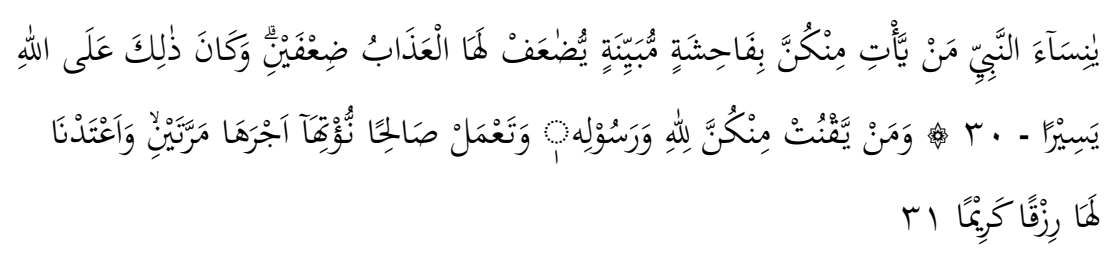




\section{$e^{\text {I-Tarbawj Widiani Hidayati \& Faisal Saleh }}$}

Artinya: "Hai isteri-isteri Nabi, Barangsiapa di antaramu yang mengerjakan perbuatan keji yang nyata, niscaya azabnya akan dilipatgandakan dua kali lipat kepadanya. Dan yang demikian itu mudah bagi Allah, Dan barang siapa diantara kamu sekalian (istri-istri nabi) tetap taat kepada Allah dan Rasul-Nya dan mengerjakan kebajikan, niscaya kami berikan pahala kepadanya dua kali lipat dan kami berikan rezeki yang mulia." (QS alAhzab ayat $30-31$ )

Menurut Hamka dalam Tafsir Al-Azhar menjelaskan bahwa istri-istri Nabi adalah orang-orang yang lebih dihormati, mereka dianggap sebagai ibunya orang-orang yang beriman. Kitab suci Al-Qur'an diturunkan di rumah mereka. Sebab itu wajib bagi mereka menjaga diri. Mereka dilarang menyerupai tingkah laku orang kebanyakan. Jika mereka berbuat suatu perbuatan yang tidak terpuji atau tidak patut yang salah dipandang mata orang banyak, maka dosa yang ditanggung akan menjadi dua kali lipat dari dosa perempuan kebanyakan. Dan jika mereka taat kepada Allah dan Rasul, disertai amal yang shalih, mereka akan mendapat dua kali lipat pula atas kebaikannya, karena mereka telah menjaga kehormatan diri dan kedudukan sebagai istri Rasul. Contoh kekejian nyata yang dapat menjadi buah bibir orang, misalnya memaki orang, mempergunjingkan orang lain, mencela, memfitnah, mencuri, dan segala dosa yang akan menjatuhkan muruah di muka umum, Maka dosanya akan dibalas dua kali lipat dari perempuan kebanyakan (Hamka 2015, 205-206)

c. Surat Al-Ahzab ayat 32

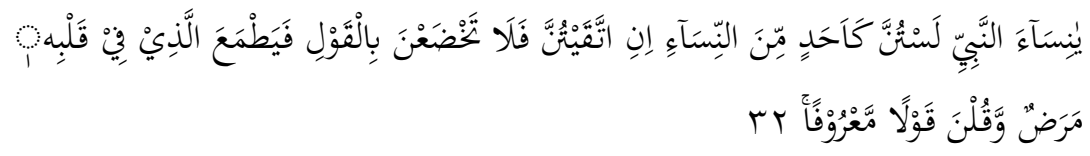


Artinya "Wahai istri-istri Nabi, kamu tidak seperti perempuanperempuan yang lain, jika kamu bertakwa. Maka janganlah kamu tunduk (melemah-lembutkan suara) dalam berbicara sehingga bangkit nafsu orang yang ada penyakit dalam hatinya dan ucapkanlah perkataan yang baik" (QS Al-Ahzab :32)

Menurut Hamka dalam tafsir Al-Azhar menjelaskan, ketika istri-istri Rasul bertakwa kepada Allah, pahala dan kedudukan mereka akan dilebihkan dari perempuan pada umumnya. Mereka menjadi suri teladan bagi orang banyak, oleh karena itu mereka harus lebih berhati-hati dalam menjaga diri. Sebagai istri Rasul, ketika berbicara hendaklah berbicara dengan tegas dan sopan, tidak genit dan tidak membuat perangai yang tidak pantas sebagai istri Rasul. ada beberapa perempuan yang dalam berbicaranya lemah gemulai, dengan kedip mata, laguan kata, dan lenggok. Maka istri Rasul tidak boleh berlaku seperti itu. Karena jika berperilaku seperti itu niscaya orang yang ada penyakit dalam hatinya akan tersinggung syahwat dan nafsu birahinya. Maka istri-istri Rasul diperintahkan untuk berucap dengan kata-kata yang pantas, Apabila berbicara timbul rasa hormat dari lawan bicaranya (Hamka 2015, 207-208)

d. Surat Al-Ahzab ayat 33

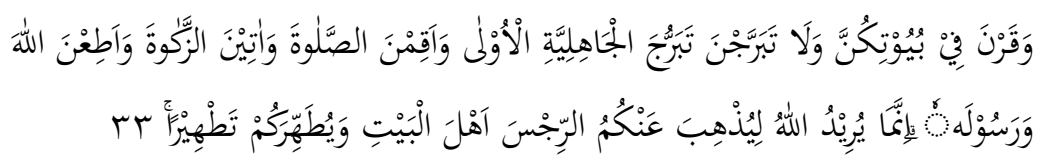

Artinya : "Dan hendaklah kamu tetap di rumahmu dan janganlah kamu berhias dan bertingkah laku seperti orangorang Jahiliyah yang dahulu, dan dirikanlah shalat, tunaikanlah zakat dan taatilah Allah dan Rasul-Nya. Sesungguhnya Allah 


\section{$e^{\text {I-Tarbawj Widiani Hidayati \& Faisal Saleh }}$}

bermaksud hendak menghilangkan dosa dari kamu dan membersihkan kamu sebersih-bersihnya." (QS Al-Ahzab : 33)

Menurut Hamka dalam tafsir Al-Azhar menjelaskan, Hendaklah istri-istri Nabi memandang bahwa rumahnya (rumah suaminya), itulah tempat tinggalnya yang tenteram dan aman. Di sanalah terdapat cinta dan kasih-sayang. Menjadi ibu rumah tangga yang terhormat. tidak berhias seperti orang jahiliah dengan tujuan agar terlihat lebih cantik, lebih menonjol, lebih menarik, lebih montok dilihat oleh laki-laki bukan muhrimnya. Istri-istri Nabi hendaknya berhiaslah secara Islam, berhias yang sopan, berhias yang tidak mencolok mata. Ini adalah pedoman pokok yang diberikan Allah dan Rasul kepada istri Nabi seluruhnya dan setiap perempuan yang beriman.

Dalam ayat tersebut juga diperintahkan untuk beribadah. Sebab ibadah kepada Allah SWT baik itu shalat, puasa dan zakat dengan kesadaran taat kepada Allah SWT dan Rasul SAW pasti akan berpengaruh terhadap perilaku hidup seharihari, termasuk kepada cara berpakaian. Istri Nabi diperintahkan untuk Bersih sebenar-benar bersihnya yaitu ialah tidak bercampurnya halal dan haram di dalam hidupnya. bersih hati dari menduakan Allah SWT. bersih dari rasa sombong terhadap sesama manusia. bersih dari tamak atas harta dunia, bersih dari hasad dan dengki kepada orang lain dan bersih dari perkataan mencela mengejek kecacatan dan kekurangan orang lain (Hamka 2015, 208-209)

Dalam ayat ini kesimpulan menurut Hamka adalah Istriistri Nabi diperintahkan berdiam di rumah, tidak behias seperti orang jahiliyah, melaksanakan ibadah dengan kesadaran taat 
kepada Allah SWT. bersih dari kemusyrikan, sifat sombong, tamak, iri, dengki, dan mencela kekurangan orang lain.

e. Surat Al-Ahzab ayat 34

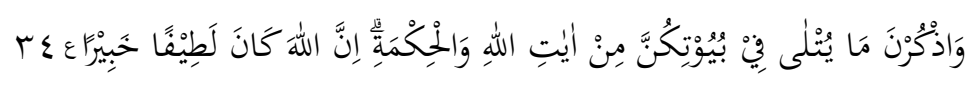

Artinya: "Dan ingatlah apa yang dibacakan di rumahmu dari ayat-ayat Allah dan hikmah (sunnah nabimu). Sesungguhnya Allah adalah Maha Lembut lagi Maha Mengetahui" (QS AlAhzab : 34)

Menurut Hamka dalam tafsir Al-Azhar menjelaskan, bahwa Rasulullah SAW tidak pernah berhenti dari membaca Al-Qur'an, baik dalam shalatnya atau di luarnya, baik sedang istirahat, ataupun dalam perjalanan pergi perang. Maka disuruhlah istri-istri Nabi untuk selalu membaca Al-Qur'an di rumahnya. Dengan lembut Allah SWT memberikan peringatan kepada wanita mulia itu bagaimana pentingnya kedudukan mereka. Pesan yang Allah SWT sampaikan kepada Rasulullah SAW untuk istri-istri Nabi menjadi tuntutan bagi setiap wanita yang beriman, seperti berpakaian yang sopan, tidak berhias secara jahiliyyah, tidak melalaikan shalat, berzakat jika ada harta cukup, dan selalu taat kepada Allah SWT. Tujuan Allah SWT atas semua itu agar memiliki rumah tangga Islami, rumah tangga yang aman damai, dikuatkan oleh ketaatan, bersih dari perangai yang tercela atau penyakit-penyakit buruk dalam hati. Dan rumah tangga Islam dengan suasana Al-Qur'an (Hamka 2015, 209-210)

Kesimpulan dalam ayat ini adalah bahwa istri Nabi diperintahkan untuk membaca Al-Quran, tidak melalaikan 


\section{$e^{\text {I-Tarbawj Widiani Hidayati \& Faisal Saleh }}$}

shalat dan zakat, berpakaian sopan, tidak berhias seperti masyarakat jahiliyah, agar terbentuk keluarga yang islami.

f. Surat al-Ahzab ayat 35

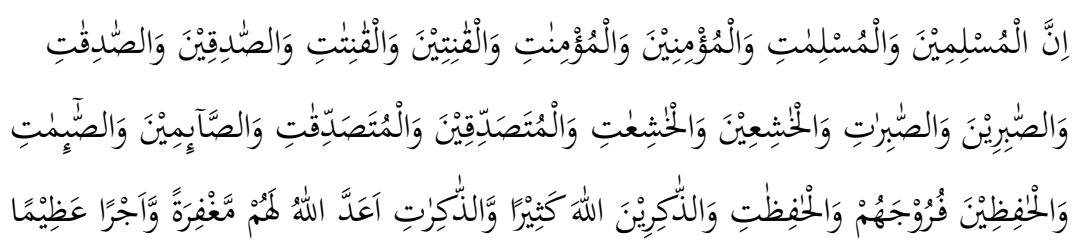

Artinya : "Sesungguhnya laki-laki dan perempuan yang muslim, laki-laki dan perempuan yang mukmin, laki-laki dan perempuan yang tetap dalam ketaatannya, laki-laki dan perempuan yang benar, laki-laki dan perempuan yang sabar, laki-laki dan perempuan yang khusyu', laki-laki dan perempuan yang bersedekah, laki-laki dan perempuan yang berpuasa, lakilaki dan perempuan yang memelihara kehormatannya, laki-laki dan perempuan yang banyak menyebut (nama) Allah, Allah telah menyediakan untuk mereka ampunan dan pahala yang besar." (QS Al-Ahzab:35)

Menurut Hamka dalam Tafsir Al-Azhar menjelaskan, bahwa Allah menyediakan ampunan atas segala kesalahan yang telah terlanjur, sebab manusia tidak luput daripada khilaf dan alpa, dan menyediakan pahala yang besar bagi Orangorang (laki-laki dan perempuan) yang tunduk kepada Allah SWT dan Rasul-nya, melaksanakan dengan baik perintahnya, tidak melepaskan diri dan membantah dari perintah Allah SWT, berkata jujur, memilih sabar ketika mendapatkan cobaan dan musibah, dan menyadari bahwa tidak kuasa untuk mengubah segala ketetapan Allah SWT, orang-orang (laki-laki dan perempuan) yang khusyuk (tekun, thuma'ninah, tenang 
dan rendah hati, merendahkan diri semata-mata kepada Allah), Gemar bersedekah (memberikan separuh harta untuk membantu orang lain), berpuasa, karena dengan berpuasa dapat menurunkan kadar syahwat, memelihara farajnya (alat kelamin kepunyaan laki-laki dan perempuan), dan selalu ingat kepada Allah, karna ingat kepada Allah SWT menjadi alat yang paling kokoh untuk mengendalikan diri dari perbuatan yang dosa (Hamka 2015, 215).

Kesimpulan dalam ayat ini Allah memerintahkan kepada umat islam, baik laki-laki atau perempuan untuk taat kepada Allah, melaksanakan perintahnya dengan baik, memiliki sifat jujur, sabar, khusyu (tekun, thumaninah, tenang, rendah hati), selain itu memerintahkan untuk berpuasa dan bersedekah, memelihara farajnya, dan selalu ingat kepada Allah. hal ini dilakukan agar manusia mendapatkan pahala yang besar dan ampunan.

\section{Meneladani Akhlak Istri Nabi}

Dari Tafsir Buya Hamka diatas, perilaku atau sikap yang dapat diteladani oleh para wanita dari akhlak ibunda orangorang beriman (Istri-istri Nabi) adalah sebagai berikut

a. Lebih memilih kehidupan Akhirat daripada Dunia dan perhiasannya (Sederhana)

Kehidupan di akhirat merupakan kehidupan yang kekal, sedangkan kehidupan di dunia adalah sementara. Dunia hanyalah sebagai panggung sandiwara, sebagai tempat untuk mengumpulkan amalan baik kita sebagai bekal di akhirat. maka sebaiknya para wanita jangan terlalu berlebihan dalam 


\section{$e^{\text {I-Tarbawj Widiani Hidayati \& Faisal Saleh }}$}

mengumpulkan harta. sebaikanya hidup sederhana jauh lebih baik. namun dalam islam juga tidak mengharamkan perhiasan dunia, asal jangan melupakan akhirat.

Perhiasan dunia itu telah disediakan oleh Allah SWT untuk hamba-hamba-Nya baik orang beriman atau orang yang tidak beriman. Namun di Akhirat nanti hanya orang-orang yang berimanlah. Menjadi kaya itu tidak masalah, bahkan bagus, karena harta dari kekayaan tersebut bisa digunakan untuk berinfaq di jalan Allah SWT, membantu banyak orang, dll. namun jangan tergoda dengan harta dunia, tetap ingat bahwa harta yang ada digenggaman kita hanyalah milik Allah SWT, dan di dalamnya ada hak-hak orang lain yang membutuhkan pertolongan. salah jika harta yang dimiliki menjadikannya sombong, takabur, harta dipergunakan untuk hal-hal yang tidak disukai. Meskipun tidak haram, tidak dilarang hidup dengan perhiasan dunia, namun Nabi SAW. sebagai pemimpin umat, sebagai pembawa contoh teladan dalam hidup ini, Beliau hidup dengan sangat sederhana dalam rumah tangganya. Dia lebih banyak memberi dari pada menerima (Hamka 2015, 194-197)

Zaman sekarang ada gaya hidup yang sedang popular dan mungkin gaya hidup ini bisa menjadi alternatif agar kita bisa hidup sederhana yaitu Minimalism Lifestyle, Gaya hidup Minimalis adalah Gaya hidup yang menggunakan sesuatu berdasarkan nilai gunanya, bukan nilainya. Gaya hidup minimalis membantu seseorang untuk memiliki kebiasaan yang lebih sederhana, karena cenderung hanya mengkonsumsi sesuatu yang benar-benar dibutuhkan. Gaya hidup ini mengajarkan untuk berhemat dan sederhana. Gaya hidup ini 
bisa menjadi gaya hidup yang akan membuat seseorang lebih menghargai nilai guna suatu barang, selain bermanfaat menjadikan penggunanya tidak boros, gaya hidup ini membuat orang lebih sederhana dan tidak berlebihan.

b. Tidak melakukan perbuatan keji karena dapat menjatuhkan kehormatan wanita

Islam telah mengistimewakan wanita, martabat wanita sangat dijunjung tinggi dalam Islam. bahkan dalam Islam kita popular dengan perkataan "Surga berada di bawah kaki ibu." begitu mulianya wanita karena dia bisa menjadi pintu syurga untuk anak-anaknya. oleh karena itu janganlah melakukan perbuatan keji, karena itu akan menjatuhkan kehormatan yang dimilikinya. kekejian yang nyata, yang dapat menjadi buah bibir orang, misalnya mempergunjingkan orang lain, mencela, memaki orang, mencuri, memfitnah dan segala dosa yang akan menjatuhkan kehormatan di muka umum (Hamka 2015, 205206) Hindari kesombongan, tamak, iri, dengki dan perbuatan buruk lainnya. Dalam Hadist yang diriwayatkan Bukhari dan Muslim, Rasulullah SAW bersabda "Sesungguhnya Allah SWT itu cemburu, dan cemburunya Allah SWT yaitu apabila ada seseorang yang melakukan perbuatan-perbuatan yang diharamkannya". (Sulastika \& Fadkan 2013, 188). Oleh karena itu tingkatkanlah takwa kepada Allah SWT dengan cara mengerjakan segala perintahnya dan menjauhi segala larangannya. salah satu sifat yang mencerminkan kehormatan wanita adalah sifat malu dalam diri wanita. Malu adalah salah satu akhlak terindah seorang wanita. Rasa malu menjadi isyarat ketinggian derajat dan wibawa wanita. Rasa malu itu 


\section{$e^{\text {I-Tarbawj Widiani Hidayati \& Faisal Saleh }}$}

mempesonakan, dan Islam sangat menjunjung tinggi rasa malu. Dalam Riwayat Bukhari muslim, Rasulullah SAW bersabda "Perasaan malu selalu mendatangkan kebaikan" (HR Bukhari dan Muslim)( Sulastika \& Al-Ikhwani 2013, 187) selain itu, dalam kitabnya Riyadhus Shalihin, Imam An-Nawawi ra, menyatakan bahwa para ulama berpendapat "Hakikat malu adalah budi pekerti yang mengajak agar meninggalkan kejelekan dan mencegah dari menghalangi orang lain"

c. Berbicara dengan baik, sopan, tegas

Wanita dianjurkan berbicara dengan baik, sopan, dan tegas.hal ini dilakukan agar tidak menimbulkan syahwat lakilaki yang menjadi lawan bicaranya. banyak wanita yang jika berbicara sengaja mendayu atau genit. hal ini sangat dilarang dalam islam. Berbicaralah dengan jelas,dan tidak bertele-tele. berhati-hati dalam berceloteh, Berusaha mengontrol lidah dalam mengucapkan perkataan yang positif, tidak menyinggung ataupun menyakiti. dalam setiap ucapan kita, kita harus ingat bahwa ucapan kita baik buruknya akan dicatat oleh Malaikat, seperti firman Allah SWT dalam Surat Qaf : 18

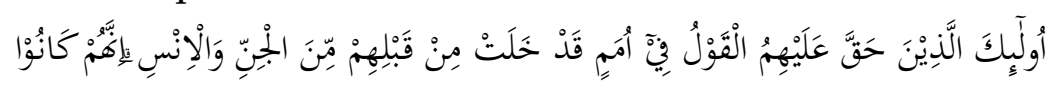

خ خسرِيْنَ 11

Artinya "Tiada suatu ucapanpun yang diucapkannya melainkan ada di dekatnya malaikat pengawas yang selalu hadir" (QS Qaf: 18). selain itu janganlah berbicara mendayu atau terihat genit. lemah gemulai, kedip mata, laguan kata, lenggok. selain bisa membuat laki-laki berhasta, hal ini juga dapat menjatuhkan kehormatan wanita 


\section{d. Berdiam Di Rumah}

Kegiatan berbahaya yang dilakukan oleh wanita adalah keluar rumah tanpa ada kepentingan dan tanpa memperhatikan norma syar'I, hal ini dapat menimbukan kemudharatan bagi orang lain dan diri sendiri. dalam Surat AlAhzab ayat 33, Allah SWT menyuruh wanita untuk berdiam di rumah dan menahan diri untuk tidak keluar rumah tanpa ada keperluan penting, karena hal itu akan membuat wanita selamat dan lebih terjaga. Abu Darda mengatakan “Sebaik-baik biaranya orang muslim adalah rumahnya. Disana dia menahan lidahnya, kemaluannya dan pandangan matanya, hindarilah bermajelis di pasar karena itu melenakan" (Sulastika \& Fadkan 2013, 101).

Rumah adalah Istana bagi wanita. Disanalah tempat kebaikan bermula. Pembentukan akhlak dan kebiasaan yang baik juga dimulai dari rumah. bahkan ibadah shalatpun bagi wanita lebih dianjurkan agar dikerjakan di rumah. sebagaimana diriwayatkan Abu Dawud dan Ibnu Mas'ud, Rasulullah SAW Bersabda "Shalatnya seorang wanita di ruang dalam rumahnya lebih utama darada solatnya di ruang tengah rumahnya dan shalatnya di dalam kamarnya lebih utama dariada shalat di ruang dalam rumahnya" walaupun shalat di masjid di larang namun di rumah bagi seorang wanita itu jauh lebih aman. (Sulastika \& Al-_-Ik_hw__an_- 2013,102).

e. Tidak berhias/berdandan berlebihan

Wanita muslimah dianjurkan untuk berpenampilan sederhana dan menurut syariat. dalam berdandan dan berpakaianpun dilarang berlebih-lebihan. karena 


\section{$e^{\text {I-Tarbawj Widiani Hidayati \& Faisal Saleh }}$}

sesungguhnya Allah SWT tidak menyukai sesuatu yang berlebih-lebihan seperti yang di firmankan Allah dalam surat Al-Araf ayat 31

Artinya: "Hai anak Adam, pakailah pakaianmu yang indah di setiap (memasuki) mesjid, makan dan minumlah, dan janganlah berlebih-lebihan. Sesungguhnya Allah tidak menyukai orangorang yang berlebih-lebihan" (QS. Al-A'raf: 31)

Wanita dilarang untuk bertabaruj. Istilah tabarruj berasal dari kata al-burj yang artinya benteng. sehingga makna tabarruj adalah keluar dari benteng dan menampakkan dirinya. artinya janganlah keluar dari benteng tutupan dan jangan pula menampakkan perhiasan dan kemolekan yang wajib ditutupi. Al-Burj juga memiliki makna berlapang dada. artinya janganlah kalian memperluas batasanya berhias melebihi batas yang sudah ditetapkan syariat. Menurut Adnan Mohamed Yuusf berpendapat bahwa tabarruj adalah wanita yang menampakkan kecantikan seluruh badan, pakaian, dan perhiasan yang dipakai, berjalan dengan patahan lenggokan yang mempesona dan menggiurkan dihadapan umum dengan tujuan menarik perhatian dan merangsang keinginan syahwat kaum lelaki (Seknun 2018, 39) Menurut Al-Quran dan Sunnah dan kesepakatan para ulama hukum tabarruj adalah haram. karena seluruh apa yang ada pada wanita adalah aurat kecuali wajah dan telapak tangan. jadi lelaki asing yang bukan mahramnya tidak boleh melihat sesuatupun dari tubuhnya, baik rambut, perhiasan, atau pakaian yang hanya pantas digunakan di rumah (Sulastika \& Al-Ikhwan 2013, 60) 
f. Beribadah (Membaca Al-Quran, Bersedekah, Berpuasa, Berdzikir)Dengan Khusyu

Allah SWT menciptakan manusia untuk beribadah kepadanya. hal ini disebutkan Allah SWT dalam Surat AdzDzariyat ayat 56 yang Artinya "Dan aku tidak menciptakan jin dan manusia melainkan supaya mereka mengabdi kepada-Ku." (QS Adz-Dzariyat : 56) Ayat diatas jelas menyebutkan tujuan diciptakannya manusia yaitu untuk beribadah, menyembah Allah SWT semata. Ayat ini mengisyaratkan pentingnya tauhid. karena tauhid adalah bentuk ibadah paling agung. Ibadah yang dilakukan seperti shalat, puasa, dzikir dll yang dilakukan dengan khusyu dan kesadaran taat kepada Allah SWT akan berpengaruh kepada sikap yang pelaku. seperti dalam surat Al-Ankabut ayat 45 yang menerangkan tentang shalat. "Sesungguhnya shalat itu mencegah dari (perbuatanperbuatan) keji dan mungkar" (QS Al-Ankabut : 45)

Menurut Imam Ibnu Qayyim, khusyuk adalah tegaknya hati di hadapan Allah dengan segala ketundukan dan kerendahan. Para ulama bersepakat bahwa tempat khusyuk adalah dalam hati, dan hasilnya timbul pada anggota tubuh dan itu merupakan manifestasinya (Lia Mega Sari 2018, 125) Menurut Hasan al-Bashri penggambaran sifat orang-orang yang khusyuk adalah sebagai berikut:

1) Kepercayaan dan keyakinan kepada Allah SWT tertanam dalam hati

2) Hati, pandangan, dan tubuh mereka senantiasa tunduk kepada Allah.

3) Merasa senang dengan kembali kepada Al-quran. 


\section{$\mathrm{e}^{\mathrm{I}-\text { Tarbawj Widiani Hidayati \& Faisal Saleh }}$}

4) Rasa takut dan penghormatan kepada Allah SWT mengalahkan hawa nafsunya.

5) Seluruh anggota tubuhnya bertahmid, memuji Allah SWT sehingga hatinya tenang dan tentram.

6) Tetap bersikap lemah lembut. Walaupun telah di bodoh-bodohi.

7) Mereka selalu mengahabiskan siang hari dan malam untuk beribadah dan berdzikir.

8) Mereka berdiri dalam shalat dan bersujud untuk Allah SWT. Dan air mata bercucuran apabila berpisah dengan Allah SWT

Dalam Islam banyak sekali amal baik yang memiliki pahala di sisi Allah SWT. diantaranya membaca Al-Qur'an, bersedekah, berpuasa dan berdzikir. Al-Quran merupakan kitab petunjuk bagi setiap muslim. sudah sepatutnya umat islam selalu membacanya. Ustman ra mengatakan bahwa Rasulullah SAW bersabda "Sebaik-baik kalian adalah orang yang mempelajari Al-Quran dan mengajarkannya (HR Bukhari) (Ahmad dan Bahri 2013, 91). Untuk itu sangat penting untuk membaca, mempelajar dan mengajarkan Al-Quran. selain itu dalam hadist lain yang diriwayatkan oleh Abdullah bin Mas'ud mengatakan Rasulullah SAW berkata "siapa yang membaca satu huruf dari bacaan Al-Quran, baginya ada kebaikan sebanyak sepuluh kebaikan. Aku tidak mengatakan Alif Lam Mim satu huruf, tapi Alif satu huruf, Lam satu huruf, dan Mim satu huruf (HR.Tirmizi). Sungguh betapa besar ganjaran bagi orang yang membaca Al-Quran (Ahmad \& Bahri 2013, 92) 
Selain membaca Al-Qur'an. amal baik yang bisa dilakukan adalah bersedakah. Sedekah yaitu mengeluarkan sebagian harta atau penghasilan/pendapatan untuk suatu kepentingan yang diperintahkan oleh agama. Sedekah juga merupakan pemberian yang dikeluarkan secara sukarela kepada siapa saja, tanpa adanya aturan waktu yang mengikat (Sanusi 2009, 9). Walaupun sedekah tidak wajib seperti zakat, namun tentunya sayang untuk meninggalkan amalan ini, karena begitu banyak keistimewaan sedekah. salah satu keistimewaannya adalah akan mengundang rezeki yang banyak dan berkah seperti firman Allah SWT dalam surat Al-Baqoroh ayat 245 yang Artinya "Barangsiapa meminjami Allah dengan pinjaman yang baik, maka Allah melipatgandakan ganti kepadanya dengan banyak. Allah menahan dan melapangkan rezeki dan kepadaNyalah kamu dikembalikan." (QS Al-Baqoroh : 245)

Selain itu Berpuasa merupakan amalan yang harus dilakukan bagi setiap muslim. Puasa dibagi menjadi 2, yaitu Puasa Wajib yaitu dikerjakan ketika bulan Ramadhan, dan ada juga puasa sunnah seperti puasa senin-kamis, puasa arafah, puasa muharam, puasa daud. dll. Dengan berpuasa, hawa nafsu menjadi lebih terkontrol, dan meningkatkan rasa syukur atas nikmat Allah SWT.

Amalan lainnya adalah Berdzikir. Zikir adalah mengingat Allah SWT dengan maksud untuk mendekatkan diri kepadaNya. Kita diperintahkan untuk berdzikir kepada Allah untuk selalu mengingat akan kekuasaan dan kebesaranNya sehingga kita bisa terhindar dari penyakit sombong dan takabbur: Allah menyuruh kita untuk berdzikir dalam firmannya yaitu dalam Surat Al-Ahzab ayat 41 yang Artinya "Hai orang-orang yang 


\section{$e^{\text {I-Tarbawj Widiani Hidayati \& Faisal Saleh }}$}

beriman, berzikirlah (dengan menyebut nama) Allah SWT dengan zikir yang sebanyak-banyaknya." (QS. Al-Ahzab : 41)

Banyak berzikir (mengingat Allah) berarti seseorang merasakan perasaan kagum dan cinta kepada Allah melebihi segalanya. dia akan merasa segala urusannya dipermudah Allah SWT karena kedekatannya dengan sang pencipta melalui dzikir. Mengingat Allah SWT artinya menghayati kekuatan dan kekuasaan yang Allah sehingga timbul perasaan takut untuk melakukan perbuatan maksiat dan akan melakukan segala kebaikan yang diperintahkan Allah SWT (Al-Ghamidi 2011, 14) g. Bersih dari segala sifat yang mengkotori hati

Setiap wanita harus membersihkan hatinya dari berbagai penyakit hati, seperti sombong, tamak, hasad dan dengki, menghina kecacatan oranglain (Hamka 2015, 208-209). karena sifat tersebut akan merugikan diri sendiri, hidup seakan hanya untuk memamerkan apa yang dimiliki dan selalu merasa tidak puas dengan apa yang dimiliki. seharusnya sebagai wanita hendaknya menghiasi diri dengan tawadhu (rendah hati), lemah lembut, dan selalu bersyukur atas nikmat yang Allah SWT berikan. dan sabar.

\section{KESIMPULAN}

Istri-istri Nabi Muhammad SAW merupakan Ibunda orang-orang yang beriman. merekalah yang menjadi panutan dan suri tauladan untuk para wanita-wanita setelahnya. Istriistri Rasulullah memiliki Akhlak yang mulia, mereka dibimbing dan diarahkan langsung oleh Nabi Muhammad 
SAW serta dengan firman-firman Allah SWT yang diturunkan untuk mereka. salah satu ayat yang membahas tentang perintah Allah SWT kepada Istri-istri Nabi adalah Surat AlAhzab ayat 28-35. walaupun dalam ayat ini Allah SWT menyeru istri-istri nabi. namun ayat ini juga ditujukan juga untuk wanita-wanita dari semua zaman, karena Al-Quran merupakan petunjuk bagi umat islam sampai hari akhir. Akhlak yang diperintahkan oleh Allah SWT kepada para wanita dalam Surat Al-Ahzab ayat 28-35 menurut Buya Hamka dalam Kitab Al-Azhar adalah Memilih kehidupan Akhirat daripada Dunia dan perhiasannya atau menerapkan kehidupan yang sederhana, Tidak melakukan perbuatan keji seperti mempergunjingkan orang lain, mencela, memaki orang, mencuri, memfitnah karena dapat menjatuhkan kehormatan wanita, Berbicara dengan baik, sopan, tegas tidak lemah gemulai, dan genit, Berdiam di rumah, Tidak berhias/berdandan berlebihan, Beribadah (Membaca Al-Quran, Bersedekah, Berpuasa, Berdzikir) dengan Khusyu, dan Bersih dari segala sifat yang mengkotori hati (Sombong, iri, tamak, dan dengki)

\section{DAFTAR PUSTAKA}

Al-Ghamidi, Dziyab. (2011). Zikir Sesudah Shalat.Jakarta : Republika Penerbit

Al-Taliyadi, Abdullah. (2008). Astagfirullah Aurat. Yogyakarta: DIVA Press

Gusmian, Islah. (2003). Khazanah Tafsir Indonesia : Dari Hermeneutika hingga Ideologi. Bandung: Teraju. 


\section{$e^{\text {I-Tarbawj Widiani Hidayati \& Faisal Saleh }}$}

Hamka, (2015). Tafsir Al-Azhar. VIII. Jakarta : Gema Insani

Hamka, (2014). Tafsir Al-Azhar.Jilid 1 Juz 1-11. Jakarta: Pustaka Panjimas

Kenang-kenangan Hidup. Jakarta: Bulan Bintang

Hidayat,Usep Taufik. (2020). “Tafsir Al-Azhar: Menyelami Kedalaman Tasawuf Hamka" Buletin Al-Turas, Vol.21, No.1.

Jambak, dan Fabian Fadhly. (2018). "Filsafat Sejarah Hamka: Refleksi Islam dalam Perjalanan Sejarah" Jurnal THEOLOGIA,Vol. 28, No. 2

Jameel, Ahmad dan Syaiful Bahri. (2013). Great Moments. Bandung: Sygma Creative Media Core

James R. Rush. (2017). Adicerita Hamka: Visi Islam sang Penulis Besar untuk Indonesia Modern. Jakarta: Gramedia Pustaka Utama.

Mega Sari, Lia (2018). “Khusyuk Dalam Al-Qur'an (Kajian Tematik)." Jurnal Nun. Vol.4, No. 2

Muhaimin Seknun, Muslih. (2018). “ Ekspolaitasi Wanita di Era Kontemporer (Studi Analisa Tafsir Tabarruj Dalam AlQur'an)." UIN SyariF Hidayatullah.

Nizar,Samsul. (2008). Memperbincangkan Dinamika Intelektual dan

Pemikiran Hamka tentang Pendidikan Islam. Jakrta : Kencana Prenada Media Group.

Rahmi, Fitri Nur. (2020). "Hamka sebagai Sejarawan : Kajian Metodelogi Sejarah terhadap Karya Hamka" Jurnal Fuaduna : Jurnal Kajian Keagamaan dan Kemasyarakatan. Vol.4, No.1

Razikin, Baidatul. (2009). 101 Jejak Tokoh Islam. Yogyakarta : eNusantara 
Rochmawati dan Sumiyati. (2020). "Miris Angka Aborsi Ilegal di Indonesia Tergolong Tinggi." https://www.viva.co.id/gaya-hidup/parenting, Agustus 2020

Sanusi, Muhammad. (2009). The Powe Of Sedekah. Yogyakarta: Pustaka Insan Madani.

Sulastika,Nunik dan Fadlan Al-Ikhwani. Rahasia Muslimah Cantik.Yogyakarta: Pro-U 